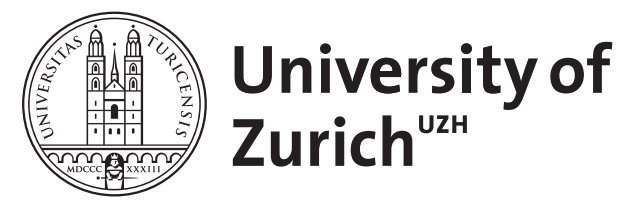

\title{
Evaluating cultural property: the economic approach
}

Frey, Bruno S

\begin{abstract}
The preservation of cultural heritage is costly and one has to decide if and which items of cultural heritage are worth preserving. A method for determining the value of cultural heritage is therefore needed. In economics, several evaluation procedures are applied. This article briefly comments on impact studies and willingness- to-pay studies (hedonic market approach and the travel cost approach) and then focuses on contingent valuation surveys. The application of contingent valuation on the arts and related problems are discussed. Finally, the article combines the evaluation methods with democratic decisions by referenda. Switzerland presents an example of referenda held on art policy
\end{abstract}

DOI: https://doi.org/10.1017/s0940739197000313

Posted at the Zurich Open Repository and Archive, University of Zurich ZORA URL: https://doi.org/10.5167/uzh-154538

Journal Article

Published Version

Originally published at:

Frey, Bruno S (1997). Evaluating cultural property: the economic approach. International Journal of Cultural Property, 6(2):231-246.

DOI: https://doi.org/10.1017/s0940739197000313 


\title{
Evaluating Cultural Property: The Economic Approach
}

\author{
Bruno S. Frey*
}

Abstract: The preservation of cultural heritage is costly and one has to decide if and which items of cultural heritage are worth preserving. A method for determining the value of cultural heritage is therefore needed. In economics, several evaluation procedures are applied. This article briefly comments on impact studies and willingness-to-pay studies (hedonic market approach and the travel cost approach) and then focuses on contingent valuation surveys. The application of contingent valuation on the arts and related problems are discussed. Finally, the article combines the evaluation methods with democratic decisions by referenda. Switzerland presents an example of referenda held on art policy.

\section{Economics and Cultural Property}

Decisions concerning cultural property are continually made by governments and public administrations. Preservation implies maintaining the stock and hindering its dilapidation and deterioration. Upkeep of the stock creates cost as the resources involved, especially the sites in the case of historic monuments, could potentially be used for alternative purposes. The cost involved consists of missed opportunities. They are real but not monetary costs, and they do not show up on any balance sheet. These opportunity costs, as economists call them, are often neglected in political and administrative decisions but should be taken into account in a socially sound decision. In addition, the preservation of cultural property also requires current funds to repair and safeguard objects. In order for these decisions to be made rationally, an evaluation of the value of cultural heritage, compared to relevant alternatives, is required.

Economics offers a wide range of approaches and techniques to help in this decision. The goal is always to assess how much satis-

* Institute for Empirical Economic Research; University of Zürich. I am grateful to Isabelle Vautravers-Busenhart and Felix Oberholzer-Gee for their helpful comments. Financial support by the Swiss National Fund, Project No. $12-42480.94$, is gratefully acknowledged. 
faction individuals derive from cultural property. Section 2 of this paper presents a short overview of the economics of art, a special branch of economics which has recently emerged. Section 3 critically analyses various procedures used in economics for evaluating cultural property. Section 4 focuses on the specific problems when these procedures are applied to cultural issues. Section 5 presents a policy approach based on constitutional choice. It proposes an integration of evaluation and decision by using direct democratic institutions, i. e., popular initiatives and referenda. Section 6 offers conclusions.

\section{Economics of Art}

The application of economic thinking to cultural issues has, over the last few years, become a well-established field. It is part of a movement designed to generalize economics as a social science not just restricted to 'the economy' but to all areas where human beings act. The Economic Approach to Human Behavior (Becker 1976; see also Hirshleifer 1985; Frey 1992) is based on the notion that individuals act rationally in the sense that they are able and willing to compare the benefits and costs of the alternatives available to them. This rational choice methodology has been transferred, and it now plays a significant role in the neighbouring disciplines of political science, sociology and history (see Coleman 1990). It has also been used in legal studies where it is called 'Law and Economics' (see, e. g., Posner 1986; Cooter and Ulen 1988). A large variety of social issues has been studied using the economic approach such as education, the natural environment, the family and crime.

The economics of art is a relative latecomer in this movement. ${ }^{1}$ The "classic" contribution is by Baumol and Bowen (1966) on the recurrent financial problems of the performing arts. It sparked immediate interest and led to the evolution of an (admittedly still small) field within economics. Surveys of art economics are provided in an article by Throsby (1994) and in various monographs such as those by Throsby and Withers (1979), Frey and Pommerehne (1989), Peacock (1993), Heilbrun and Gray (1993), and Benhamou (1996). Collections of articles have been edited by Blaug (1976) and, more recently, by Towse and Khakee (1992), Peacock and Rizzo (1994), and Ginsburgh and Menger (1996).

The Association of Cultural Economics, International organises a biannual world conference with a corresponding volume of selected contributions and edits the Journal of Cultural Economics. ${ }^{2}$ There is an increasing number of conferences devoted to specialized issues in the arts. Somewhat surprisingly, the topic of cultural property, at least in the sense of heritage, has so far received scant attention, but there are signs that the situation is beginning to change. 


\section{Evaluation Procedures}

\subsection{Impact Studies}

The most popular way to measure the "value" of a piece of cultural property is to look at the monetary revenue created. Thus, for example, one looks at the expenditures incurred by the visitors to a theatre or opera house (entry price, restaurant meals, transportation, hairdressing, formal clothes, etc.) and calculates the multiplier effect induced by these expenditures (e. g., the restaurant has to consider various resources and pay various persons). The way impact studies measure the monetary income is not correct because they fail to record the social surplus (i. e., the difference between gross social value and cost; income for labour is a cost, not a benefit).

Though such studies are largely in demand by the suppliers of cultural services (see, e. g., Vaughan 1980 for the Edinburgh Festival or O'Hagan 1992 for the Wexford Opera Festival), they do not adequately capture the social value of a cultural object. These studies completely disregard those values not reflected in the market:

(1) A person may benefit from the supply of culture even if he or she does not currently use it. This option value is not reflected in the market because no effective demand is exerted.

(2) A positive existence value of art exists which also prevails for those not using the art. In particular, this value may exist for historic buildings which, once destroyed, are difficult or impossible to rebuild.

(3) The preservation of art may have a positive bequest value for future generations which cannot express their preferences in currently existing markets.

(4) Cultural property and other art objects may have a significant prestige value even for those who do not use their services or who are not interested in art at all. Examples are the Scala in Milan or the Louvre in Paris which both provide a sense of national pride and help to maintain national cultural identity.

(5) Artistic buildings and activities may have an educational value. They help a society foster creativity, improve the capacity of cultural evaluation and develop aesthetic standards and aspects which benefit all persons in a society and which are unlikely to be adequately internalized by the price system.

Empirical research has shown that, depending on the cultural sector considered, these non-market values are often of significant size. They need to be taken into account when undertaking a benefit-cost calculation of whether a cultural activity or a price of cultural property should be supported by the public. The use of impact studies which disregard these values risks a great peril. It may well turn out that a non-artistic activity or object generates even higher revenues. If one relies exclusively on the logic of impact studies, one would 
then undertake these non-artistic activities, e. g., demolishing a historic building and substituting it with a sports stadium or a shopping centre. (Good) economists take great pains not to fall into this trap, though they are often offered substantial grants to perform such studies.

\subsection{Willingness-to-Pay}

There is a well-established way to evaluate non-marketed goods: willingness-to-pay values measure the maximum price which a person would pay for the object or project in question. Several methods are available and have been employed empirically (Cropper and Oates 1992; see also Pommerehne 1987; Mitchell and Carson 1989). The two most widely-used procedures are:

(1) The hedonic market approach which derives the values attributed to a cultural object by looking at private markets which indirectly detect the utility persons enjoy. Consider a historic palace situated in a beautiful park located in the city centre. If all other things are equal, an individual attributing a value to the palace and the park would be prepared to accept an equivalent job near the palace at a lower wage than elsewhere. The difference between this lower wage and the wage elsewhere constitutes an indirect monetary measure of that particular individual's evaluation of the palace and the park. The value attributed can also be derived from the higher rents, house and land prices which people are prepared to pay because they enjoy the palace and the park. Again, the price difference compared to an equivalent apartment, house or piece of land elsewhere constitutes a monetary evaluation of the palace and the park. While such an indirect measure of the value of culture is intriguing, it is not able to capture the values mentioned above. The option, existence and prestige values as well as the bequest value and the educational value in the case of house and land prices are not integrated.

The hedonic market approach is quite intricate. Its reliability depends on two major conditions: the private markets for labour and housing or land must be in perfect equilibrium, and the "ceteris paribus" (all else equal) assumption needed for the comparison must be fulfilled. These conditions are rarely completely met so that the corresponding monetary evaluation of the cultural object is biased, often to an unknown extent.

(2) Another widely-used method is the travel cost approach. It lends itself in particular to measuring the value of an object of historic heritage, e. g., a castle situated in the countryside. People spend money on the trip leading to the castle as well as for the entry ticket. This constitutes a bottom measure for the utility they expect to derive from the visit. 
The travel cost method relies on two major assumptions: the object in question must be the only purpose of the trip and the trip itself does not yield any pleasure. In many cases, these assumptions do not hold because people tend to combine various goals when making a trip. Moreover, the castle, in our example, may be located in an attractive landscape or the trip is pleasurable because of one's company so that the cost expended no longer reflects the utility attributed to the castle. Moreover, few of the non-market values listed above are taken into account; the method captures, at best, part of the prestige and educational value. Even under ideal conditions, the cost expended does not reveal the full value attributed to the cultural object because it may well be that people would have been willing to travel longer distances and to pay a higher entry price in order to enjoy the object.

As the essential assumptions required by the two procedures are, in many cases, not sufficiently met in practice to make the respective methods seriously applicable, most economists have turned to "Contingent Valuation" (CV). It uses sample surveys to elicit the willingness-to-pay for cultural objects. The questionnaire involves a hypothetical situation, and the term 'contingent' refers to the constructed or simulated market presented in the survey.

\subsection{Contingent Valuation Surveys}

Surveys have been widely used by economists to estimate people's willingness-to-pay. Over the years, considerable experience has been gained. In their bibliography, Carson, et al. (1994) list almost 1700 studies in over 40 countries. Early examples include evaluations of a reduction in household soiling and cleaning (Ridker 1967), the right to hunt waterfowl (Hammack and Brown 1974), reduced congestion in wilderness areas (Cicchetti and Smith 1973), improved air visibility (Randall, Ines and Easterman 1974) and the value of duck hunting permits (Bishop and Heberlein 1979). Most survey studies evaluate objects in the natural environment; however, there are also other applications including the reduced risk of dying from heart attack (Acton 1973), the reduced risk of respiratory disease (Krupnick and Cropper 1992) and even improved information about grocery store prices (Devine and Marion 1979).

A politically important, recent Contingent Valuation study (Carson et al. 1992) has been used to measure the environmental damage caused by the supertanker Exxon Valdez which ran aground in March 1989 in Prince William Sound, Alaska, spilling 11 million gallons of crude oil into the sea. The enormous sums of money involved in the litigation associated with the Alaska oil spill has further drawn the attention of the economics community to this particular survey method. As a consequence, the Contingent Valuation method has come under careful scrutiny in the profession. The United States National Oceanic and Atmospheric Administration 
(NOAA) hired two Nobel prize winners (Kenneth Arrow and Robert Solow) to co-chair a panel with the task of assessing the Contingent Valuation method. The bottom line of the panel report (Arrow et al. 1993) concludes "that CV studies can produce estimates reliable enough to be the starting point of a judicial process of damage assessment, including lost passive-use values." The term "passive-use values" refers to the non-use values of the environment composed of existence, option and bequest benefits. However, the report stated a large number of stringent requirements for that conclusion to hold. The most important are:

(1) personal interviews rather than telephone surveys which, in turn, are preferable to mail surveys;

(2) the environment in which the object to be evaluated is situated must be described accurately and understandably;

(3) it must be made clear for what other purposes the money can be spent if the project or policy is not undertaken, i. e., the budget constraint must be well specified;

(4) the respondents must be reminded of the substitutes for the commodity in question, e. g., it must be stated what other castles or palaces can be visited if the one in question were demolished;

(5) it must be ascertained that the respondent understands the question and the underlying choice.

\section{Applications of Contingent Valuation Surveys to the Arts}

\subsection{Existing Studies}

To date, only a few studies use the Contingent Valuation procedure for issues of culture. There have been attempts to measure the broad support for the arts in terms of the desired government expenditures (e. g., Throsby and Withers 1983, Morrison and West 1986). I am aware of only two serious studies in which the procedure has been applied to measure the willingness-to-pay for specific cultural objects: Bille Hansen (1995) uses it for the Royal Danish Opera in Copenhagen, and Martin (1994) uses it for the Musée de la civilisation in Quebec.

Yet, in cultural policy, decisions are continually made whether to preserve an object of cultural heritage, to demolish it or at least to let it deteriorate beyond repair. Relevant examples are the castles or palaces mentioned above. Others are villas in the "fin-de-siècle" style or "Jugendstil" which, on the one hand, are worth preserving and which, on the other hand, are situated in locations which can be most profitably used for other purposes and are often very expensive to repair and put to good use. Another example are the "galleries" (shopping malls of the late $19^{\text {th }}$ and early $20^{\text {th }}$ centuries) in Paris and elsewhere which are dilapidated but which could still be restored. 
It makes less sense to evaluate the benefits and costs of preserving the Colosseum or the Tour Eifel because it is beyond one's imagination that they would be torn down. If, for some reason, a demolition were planned, a Contingent Valuation survey would not change the result a bit.

\subsection{Problems of Survey Studies in the Arts}

In this section, the paper concentrates on specific problems which arise when Contingent Valuation is applied to cultural heritage. Four issues will be discussed.

\section{2:1 Marginal versus Total Choices}

Survey studies typically confront the respondents with an "all or none" choice or with an indivisible good. Either the villa or the gallery is to be totally preserved or not at all. Bille Hansen (1995) explicitly states, for example, that the Royal Danish Theatre is to be run at the present activity level. Clearly, it is always possible to vary the level, although that option is routinely and fervently rejected by the suppliers. One possibility would be to give up the ballet section or the opera section, and the respondents could then be asked for their willingness-to-pay for these different activity levels. Even a villa or a gallery could be partially preserved without completely destroying the respective historical value. Constructing such a demand curve for various "sizes" or "qualities" of the cultural good is, in principle, possible but would involve much additional work because the survey must exactly specify the various levels and do it in a form understandable to the respondents.

\subsubsection{Non-Optimising Choices}

This second issue is closely connected to the first but is not identical. The survey approach does not include an optimising algorithm, i. e., the historic object is presented to the respondents as it is. It is (implicitly) assumed that supply is already efficient in two respects:

(1) The object's activities are so perfectly run that no improvement is possible without having to give up some other goal. This assumption is, to say the least, heroic; it is known from extensive research in the economics of art that there exist considerable opportunities for improvements in technical efficiency.

(2) Contingent Valuation studies also assume efficiency in the sense that the consumers' preferences are met. Again, art economists provide overwhelming evidence to the contrary. In particular, not only the directors of theatres and museums but also the directors of historic cities tend to follow their own preferences which may systematically and significantly deviate from what the average citizens, who are relevant in willingness-to-pay studies, desire. 
Survey studies do not take into account much of the insights and knowledge which have been accumulated in cultural economics. Thus, excellent opportunities for improvements in the presentation and, therefore also, preservation of art are overlooked. A most useful contribution of an economist in safeguarding our cultural heritage is to suggest already known or innovative ways to put it to good use. Thus, for example, a Roman arena can be employed for all kinds of artistic and popular sports performances and festivities so that the respondents are likely to have a much larger willingness-to-pay because the arena has been filled with life.

\subsubsection{What values?}

It is not obvious what preferences should enter Contingent Valuation studies in the arts and elsewhere. Two aspects are of particular importance:

(1) Psychological anomalies ${ }^{3}$ play a major role. Most importantly, the disparity between gains and losses matters. This endowment effect leads to a major difference between willingness-to-pay and willingness-to-accept which, according to standard economic theory, should be roughly equal. In a study of the valuation of the environment by duck hunters, for example, the willingness-to-pay to save marsh area used by ducks was, on average, $\$ 47$ per hunter, but the hunters would, on average, demand $\$ 1,044$ (or 22 times as much) to accept the identical loss (Hammack and Brown 1974). The endowment effect has been associated with the idea of the "patrimoine nationale' of art (Frey and Pommerehne 1987). A loss is highly valued. Imagine France losing the Mona Lisa, Rome losing the Colosseum or Florence losing the Uffizi. Imagine, however, that none of these historic treasures ever existed. Does France really need the Mona Lisa? It has hundreds of other masterpieces in its museums. Does Rome really need the Colosseum? It has the whole Forum Romanum nearby with spectacular triumphal arches. Does Florence really need the Uffizi? It has other important museums as well as the Dome. If this were true, citizens would express a low willingness-topay to acquire these objects of culture. The question is what evaluation is to count or, equivalently, what initial state is envisaged. Taking the status quo and enquiring how high would be the evaluation of a loss speaks much for itself. However, under a long-term perspective, the issue looks different. Once it is hypothesized that an art object has never existed or has been lost for a long time, the endowment effect vanishes and the evaluation of the respective art object becomes dramatically lower.

(2) Art is international, and it is no rare occurrence that a country's culture is more highly valued by foreigners than by the inhabitants of the country itself. Yet, Contingent Valuation studies normally survey only the inhabitants. Thus, Bille Hansen (1995) only surveyed 
residents of Denmark for her study of the Royal Theatre. While it may be admissible in this case, in other cases it would be wholly mistaken. The Maya ruins in the jungles of Central America, for example, are probably valued less by the inhabitants than by the North Americans and Europeans who would probably express a rather high willingness-to-pay for the ruins' existence.

It might be argued that at least part of that willingness-to-pay would be expressed by local respondents who include the prospects of attracting tourists in their evaluation. Option values, however, are not taken into account as they do not lead to actual visits. Even under ideal conditions, only a minor part of the option value can be appropriated by the local residents in the form of royalties for the pictures taken and films made of the art.

A similar problem arises with future generations who cannot be surveyed at all. Part of the value is taken into account by the bequest motive of the respondents, but the questionnaire again has to be very carefully designed. For objects of cultural heritage, the problem of capturing the willingness-to-pay of future generations is particularly intense because the issues involved are often extremely long-term and it is known that future preferences with respect to art systematically deviate from the values of the living generation. Older people tend to attach much less value to contemporary art than is attributed by subsequent generations, at least from the vantage point of the latter. $^{4}$

\subsubsection{Specific versus Statistical Values}

Individuals evaluate specific objects, such as a particular cultural monument, quite differently than a non-specified or statistical object. This disparity was first found in the case of human lives (Schelling 1984). People are prepared to spend enormous sums to save the life of an identified person such as a child who has fallen into a well. They are prepared to spend much less on efforts to save yet unidentified lives by, for example, spending resources to reduce the number of deadly accidents on a road. This disparity mirrors the two kinds of Contingent Valuation studies in art mentioned at the beginning. It would follow that respondents would indicate a much higher willingness-to-pay for the Royal Danish Theatre and the Musée de la civilisation Quebec than for public art expenditures in general.

\subsection{Beneficial Aspects}

As with any other evaluation method, Contingent Valuation surveys are confronted with problems and difficulties. Yet, it is important to see that they also provide major insights.

\subsubsection{Serious Research Effort}

Contingent Valuation studies promise to yield worthwhile results because they force the researchers to undertake a determined and 
extensive analysis of the art object in question. The questionnaire has to meet stringent requirements to be usable at all. Even more importantly, the representative survey approach addresses both visitors and non-visitors. The usefulness of a Contingent Valuation study is increased further if the assumptions made in the course of the analysis are discussed and systematically varied so that the robustness of the results can be evaluated.

\subsubsection{Indirect Benefits}

Contingent Valuation studies have the major advantage of being able to capture existence, option and bequest values: "the contingent valuation method would appear to be the only method capable of shedding light on [such] potentially important values" (Portney 1994: 14). That such non-use values are of particularly great importance in the arts has already been pointed out.

\subsubsection{Quality not only Quantity}

A frequent charge by "arts people" is that economic approaches can only measure the quantity of art but not the quality. Contingent Valuation proves such accusations to be wrong. The number of visits to a theatre, a museum or a monument does not matter as much as how highly a visit is valued by the individuals concerned. Moreover, nonuse values are also integrated. The respective evaluations are made comparable to alternatives, in particular to other uses of tax funds or to lower taxes and higher private consumption.

\section{Combining Evaluation and. Decision by Referenda}

Public decisions on culture are taken in the politico-economic process in which politicians, public officials, interest groups and citizens/taxpayers interact within a given constitutional framework. Thus, some cultural decisions are to be taken on the local level, others at the regional, cantonal or provincial level and still others at the national level. These decisions are normally very complex due to the many interactions. However, the budgetary situation and the administrative constraints are always highly significant, and they determine, to a large extent, how much money is spent in various ways for the arts. In contrast, willingness-to-pay studies which relate to social welfare and not to political exigencies are of little importance. Some actors may under some circumstances use the results of such studies to bolster their arguments provided they suit their interests.

The major problem with the willingness-to-pay studies based on social welfare is that they are divorced from political decisions. Therefore, it is proposed here that the willingness-to-pay is revealed 
and, at the same time, the decision is taken by popular referenda. This proposal is theoretically cogent. Indeed, the NOAA-panel headed by Arrow and Solow (Arrow et al. 1993) demanded that 'contingent valuation should [use] the referendum format' (Portney 1994: 9). A well-designed Contingent Valuation study thus imitates a popular referendum. Why then should it not be employed? As a decision-making mechanism, referenda have many advantages over democratic decisions via representation. In particular, referenda avoid the principal-agent problem and constitute an effective barrier against the 'classe politique' (see, e. g., Frey 1994; Bohnet and Frey 1994). Both aspects are of particular importance with respect to cultural decisions because politicians and bureaucrats tend to have more room for discretion in this area than elsewhere. It has been empirically shown (Frey and Pommerehne 1990, chapter 10) that individual citizens not only evaluate the user-values but also existence, option and bequest values in their vote.

Five arguments are often raised against the use of popular referenda for cultural policy.

\subsection{Incapable Citizens}

It is claimed that voters are both uninformed and unintelligent with respect to cultural affairs and, therefore, cannot be trusted to make "good" decisions. The criticism concerning the lack of information is doubtful because when citizens are given the power to decide, they will inform themselves. Citizens do not acquire much information today as they cannot decide anything. The state of information is not given but endogenous. The discussion process induced by the referendum produces the necessary information to decide, a service which the researcher has to perform artificially when undertaking a survey. As for the lack of intelligence with respect to art, referenda are, of course, in exactly the same position as all willingness-to-pay methods. In all cases, individual preferences and not the supposedly superior insights of a cultural/political elite are important.

\subsection{Superficial Citizens}

It is also claimed that voters do not take referendum decisions seriously. It is quite true that they are "low cost" (see Kliemt 1986; Kirchgässner and Pommerehne 1993), but this applies equally to Contingent Valuation procedures (but not to the travel cost method which looks at revealed behaviour). One may argue that individuals take the response to a survey still more lightly because the situation is purely hypothetical. Referendum voting is, moreover, connected with significant personal cost when the pre-referendum discussion is intensive. In that case, not having and not being able to defend a particular position (and vote decision) is negatively sanctioned by the citizen's social environment (for this argument, see Frey 1994). 
Intensive discussions are not atypical for referenda on culture. An example is the vote on the purchase of two Picasso paintings in the city of Basle (see Frey and Pommerehne 1990, chapter 10).

\subsection{Propaganda Influence}

In referenda, the interest groups and parties seek to affect the vote by newspaper, radio and television campaigns. However, an open society is defined by admitting propaganda from all sides and it is, therefore, not a priori clear what the effect of propaganda is on referendum decisions. Normally, the cultural interests are well organized and motivated; they emanate from the highly subsidised cultural institutions such as museums, theatres, orchestras and other arts organizations. Individuals uninterested or opposed to the arts are generally less educated with lower income and lower levels of political participation. They are often weakly organized, so their propaganda influence is small. Art lovers should not, therefore, be afraid of the propaganda activity associated with referenda.

\subsection{Restricted Participation}

Referendum participation is constrained in two ways:

(1) Citizens decide not to vote. Non-participating citizens are parallel to those individuals who refuse to answer the survey questions in a Contingent Valuation study. The motivation is not the same but is likely to be similar. The major reason for non-participation is the lack of interest in cultural issues and it may, therefore, be argued that it is not as detrimental if such people do not vote or respond.

(2) Some people, especially foreigners and future generations, are formally excluded from voting. As we have seen, this also applies to surveys. Some of these interests are, however, taken into account by the voters. As far as these interests are connected with business (tourism), propaganda is used to motivate voters to decide in their favour.

\subsection{Amount of Knowledge Gained}

In a popular referendum, voters may only decide between "yes" and "no," while in surveys more information can be collected. This is a clear advantage of such studies. However, referenda outcomes can be analysed by cross-section (and sometimes time-series) methods which yield additional information. It has, for instance, been possible to isolate various non-user effects (see Frey and Pommerehne 1990, chapter 10). Moreover, while the referendum decision itself is restricted to yes or no, preference intensity is partly reflected in the decision whether to participate, and the fact that the exercise of one's preference is connected with a binding democratic decision tends to increase the seriousness with which the decision is taken. 
The five arguments often raised against the use of referenda in the arts are thus not compelling. Either they are unfounded as such, for example, the citizens are incapable, or the shortcomings are shared by other methods of evaluating cultural property. No approach is ideal, yet we should use those methods which best serve the purpose at hand. Popular referenda are certainly a good procedure in many cases, especially as they combine evaluation and decision making. This is the crucial advantage over all other methods, including Contingent Valuation surveys.

\section{Conclusions}

Our discussion has shown that willingness-to-pay procedures and, in particular, Contingent Valuation are useful but have a decisive disadvantage in that they are not related to political decisions. Popular referenda combine the evaluation of competing alternatives with democratic decisions. It has been argued that this combination is particularly relevant and beneficial for cultural decisions. Academics who want to contribute to preserving the cultural heritage should not restrict themselves to undertaking willingness-to-pay studies but should suggest constitutional changes allowing and prescribing the use of popular referenda for cultural decisions.

Referenda on issues of culture and cultural heritage, in particular, are feasible. Indeed, in Switzerland such referenda are routinely undertaken at all governmental levels. While at the national level the propositions relate to general laws and constitutional provisions on the support of the arts, at the cantonal and even more so at the communal level citizens decide directly on the amount of subsidies and other monetary support for culture. As empirical research has shown (see Frey and Pommerehne 1995), voters are prepared to support a substantial share of such cultural outlays. Indeed, they tend to be more favourably inclined to support culture as opposed to other types of expenditures. It can, of course, be argued that Switzerland is different from other countries. This is certainly true. What the Swiss example does show, however, is that referenda on issues of cultural heritage can be undertaken and that one can put trust in the voters' judgement.

\section{Notes}

1 There are precursors in Europe. Thus, early contributions in German are Kindermann (1903), Lux (1906) and Drey (1910).

2 The addresses are: Professor Neil O. Alper, Executive Secretary-Treasurer, Association for Cultural Economics International, Department of Economics, Northeastern University, Boston, Massachusetts 02115; Journal of Cultural Economics, Kluwer Academic Publ., P. O. Box 322, 3300 AH Dor- 
drecht, The Netherlands, or P. O. Box 358, Accord Station, Hingham, Mass. 02018-0358.

3 See, e. g., Kahneman, Slovic and Tversky 1982; Arkes and Hammond 1986; Bell, Raiffa and Tversky 1988; Dawes 1988; Frey and Eichenberger 1989; Thaler 1992.

4 Today's younger generation values Jugendstil-monuments more highly than the past generation which produced it. On the other hand, not all that was called 'art' in the past is considered as such today.

\section{References}

Acton, Jan (1973). Evaluating Public Progress to Save Lives: The Case of Heart Attacks, RAND Research Report R-73-02. Santa Monica: RAND Corporation.

Arkes, Hal R. and Kenneth R. Hammond (eds) (1986). Judgement and Decision Making: An Interdisciplinary Reader. Cambridge: Cambridge University Press.

Arrow, Kenneth J., Robert S. Solow, Edward Leamer, Paul Portney, Ray Radner and Howard Schuman (1993). "Report of the NOAA-Panel on Contingent Valuation," Federal Register 58 (10): 4601-4614.

Baumol, William J. and William G. Bowen (1966). Performing Arts - The Economic Dilemma. Cambridge, Mass: Twentieth Century Fund.

Becker, Gary S. (1976). The Economic Approach to Human Behavior. Chicago: Chicago University Press.

Bell, David E., Howard Raiffa and Amos Tversky (eds) (1988). Decision Making. Descriptive, Normative and Prescriptive Interactions. Cambridge: Cambridge University Press.

Benhamou, Francoise (1996). L'économie de la culture. Paris: Editions La Découverte.

Bille Hansen, Trine (1995). A CV Study of Willingness-to-pay for the Royal Theatre in Copenhagen. Mimeo. AKF, Institute of Local Government Studies, Copenhagen.

Bishop, Richard C. and Thomas A. Heberlein (1979). Measuring Values of Extramarket Goods: Are Indirect Measures Biased? American Journal of Agricultural Economics 61: 926-30.

Blaug, Mark (ed.) (1976). The Economics of the Arts. London: Martin Robertson.

Bohnet, Iris and Bruno S. Frey (1994). Direct-Democratic Rules: The Role of Discussion. Kyklos 47: 341-354.

Carson, Richard, et al. (1992). A Contingent Valuation Study of Lost Passive Use Values Resulting From the Exxon Valdez Oil Spill, Report to the Attorney General of the State of Alaska, prepared by Natural Resource Damage Assessment, Inc., La Jolla, California.

Carson, Richard, et al. (1994). A Bibliography of Contingent Valuation Studies and Papers. La Jolla, California: Natural Resources Damage Assessment, Inc.

Cicchetti, Charles J. and Kerry Smith (1973). Congestion, Quality Deterioration, and Optimal Use: Wilderness Recreation in the Spanish Peaks Primitive Area. Social Science Research 2: 15-30.

Coleman, James S. (1990). Foundations of Social Theory. Cambridge, MA: Harvard University Press.

Cooter, Robert D. and Thomas Ulen (1988). Law and Economics. Glenview, IL: Scott, Foresman.

Cropper, Maureen L. and William E. Oates (1992). Environmental Economics: A Survey. Journal of Economic Literature 302:675-740. 
Dawes, Robyn M. (1988). Rational Choice in an Uncertain World. San Diego and New York: Harcourt, Brace, Jovanovich.

Devine, D. Grant, and Bruce Marion (1979). The Influence of Consumer Price Information on Retail Pricing and Consumer Behaviour. American Journal of Agricultural Economics 61 (May): 228-37.

Drey, Paul (1910). Die wirtschaftlichen Grundlagen der Malkunst. Stuttgart and Berlin: Cotta.

Frey, Bruno S. (1992). Economics as a Science of Human Behaviour. Boston and Dordrecht: Kluwer.

Frey, Bruno S. (1994). Direct Democracy: Politico-Economic Lessons from Swiss Experience. American Economic Review 84 (May): 338-348.

Frey, Bruno S. and Reiner Eichenberger (1989). Should Social Scientists Care about Choice Anomalies? Rationality and Society 1: 101-122.

Frey, Bruno S. and Werner W. Pommerehne (1987). International Trade in Art: Attitudes and Behaviour. Rivista Internazionale di Scienze Economiche e Commerciali 34 (6): 465-486.

Frey, Bruno S. and Werner W. Pommerehne (1989). Art: An Empirical Inquiry. Southern Economic Journal 56 (Oct.): 396-409.

Frey, Bruno S. and Werner W. Pommerehne (1990). Muses and Markets. Explorations in the Economics of Art. Oxford: Blackwell.

Frey, Bruno S. and Werner W. Pommerehne (1995). Public Expenditure on the Arts and Direct Democracy: The Use of Referenda in Switzerland. Cultural Policy 2 (1): 55-65.

Ginsburgh, Victor A. and Pierre-Michel Menger (eds) (1996). Economics of Arts. Selected Essays. Amsterdam: Elsevier/North Holland.

Hammack, J. and Gardner Brown (1974). Waterfowl and Wetlands: Toward Bioeconomic Analysis. Amsterdam: North Holland.

Heilbrun, James and Charles M. Gray (1993). The Economics of Art and Culture

- - An American Perspective. Cambridge: Cambridge University Press.

Hirshleifer, Jack (1985). The Expanding Domain of Economics. American Economic Review 75 (May): 53-68.

Kahneman, Daniel, Paul Slovic and Amos Tversky (eds) (1982). Judgement under Uncertainty: Heuristics and Biases. Cambridge: Cambridge University Press.

Kindermann, Carl (1903). Volkswirtschaft und Kunst. Jena: Fischer.

Kirchgässner, Gebhard and Werner W. Pommerehne (1993). Low-cost Decisions as a Challenge to Public Choice. Public Choice 77 (September): 107-115.

Kliemt, Hartmut (1986). The Veil of Insignificance. European Journal of Political Economy 2/3: 333-344.

Krupnick, Alan and Maureen Cropper (1992). The Effect of Information on Health Risk Valuation. Journal of Risk and Uncertainty 2: 29-48.

Lux, Joseph A. (1906). Volkswirtschaft des Talents: Grundsätze einer Volkswirtschafslehre der Kunst. Leipzig: Voigtländer.

Martin, Fernand (1994). Determining the Size of Museum Subsidies. Journal of Cultural Economics 18: 255-270.

Mitchell, Robert C. and Richard T. Carson (1989). Using Surveys to Value Public Goods: The Contingent Valuation Method. Washington, D. C.: Resources for the Future.

Morrison, William G. and Edwin G. West (1986). Subsidies for the Performing Arts: Evidence on Voter Preferences. Journal of Behavioral Economics 15 (Fall): $57-72$.

O'Hagan, John W. (1992). The Wexford Opera Festival: A Case for Public Funding? In: Ruth Towse and Abdul Khakee (eds), Cultural Economics. Berlin: Springer: $61-66$. 
Peacock, Alan T. (1993): Paying the Piper, Culture, Music and Money. Edinburgh: Edinburgh University Press.

Peacock, Alan and Idle Rizzo (1994). Cultural Economics and Cultural Policies. Dordrecht: Kluwer.

Pommerehne, Werner W. (1987). Präferenzen für Öffentliche Güter. Ansätze zu ihrer Erfassung. Tübingen: Mohr (Siebeck).

Portney, Paul R. (1994). The Contingent Valuation Debate: Why Economists should Care. Journal of Economic Perspectives 8 (4): 3-17.

Posner, Richard A. (1986). The Economic Analysis of Law. $3^{\text {rd }}$ ed. Boston: Little \& Brown.

Randall, Alan, Berry C. Ives, and Clyde Eastman (1974). Bidding Games for Valuation of Aesthetic Environmental Improvements. Journal of Environmental Economics and Management 1: 132-149.

Ridker, Ronald (1967). The Economic Cost of Air Pollution. New York: Praeger.

Schelling, Thomas C. (1984). The Life You Save May Be Your Own. In: Choice and Consequence. Perspectives of an Errant Economist. Cambridge, MA and London, England: Harvard University Press: 113-146.

Thaler, Richard H. (1992). The Winner's Curse. Paradoxes and Anomalies of Economic Life. New York: Free Press.

Throsby, David C. (1994). The Production and Consumption of the Arts: A View of Cultural Economics. Journal of Economic Literature 33: 1-29.

Throsby, David C. and Glenn A. Withers (1979). The Economics of the Performing Arts. London and Melbourne: Arnold.

Throsby, David C. and Glenn A. Withers (1983). Measuring the Demand for the Arts as a Public Good: Theory and Empirical Results, In: William S. Hendon and James L. Shanahan (eds), Economics of Cultural Decisions. Cambridge, MA.: Abt, 177-191.

Towse, Ruth and Abdul Khakee (eds.) (1992). Cultural Economics. Berlin: Springer.

Vaughan, David Roger (1980). Does a Festival Pay? In: James L. Shanahan, William S. Hendon and Alice J. MacDonald (eds), Economic Policy for the Arts. Cambridge, Mass.: Abt: 319-331. 